\section{Methods to Assess Potential Chloride Stress in Citrus: Analysis of Leaves, Fruit, Stem-xylem Sap, and Roots}

\author{
Eran Raveh ${ }^{1}$
}

AdDitionAL INDEX words. juice, rootstock, salinity

SumMary. Chloride stress in commercial citrus is predominantly a result of increased osmotic pressure in the plant as a result of excess chloride. The source of the chloride is usually from the soil solution, where it is absorbed by the roots. After being absorbed, chloride flows through the xylem in the transpiration stream to the shoot, where it is accumulated by transpiring tissues such as leaves and fruit. Monitoring chloride concentration along any of these steps can be used to assess potential stress in the tree. Since some of these tissues tend to accumulate chloride (fruit and leaves) while others do not (root and xylem), analyses should be interpreted within the context of these differences. Having high chloride concentration in roots or xylem-water at a specific sampling time does not necessarily mean that leaves have already accumulated chloride to a toxic level, while having high chloride concentration in fruit or leaf analysis does not necessarily mean that the trees are still being exposed to high salinity in the soil solution. The advantages of the various analyses, as well as their difficulties, are discussed. It was concluded that a combination of xylem sap chloride analysis and leaf chloride analysis are the most useful tools for assessing potential chloride stress in citrus trees.

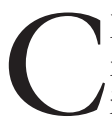

hloride stress in commercial citrus is predominantly a result of its accumulation in the leaves to a toxic level (Story and Walker, 1999). The source of the chloride is usually the soil solution, where it is absorbed

Institute of Horticulture, Agricultural Research Organization, Gilat Research Center, Mobile Post Negev, 85280, Israel.

${ }^{1}$ To whom reprint requests should be addressed. Email: eran@agri.gov.il; phone: +972-8-9928670; fax: +972-8-9926485.

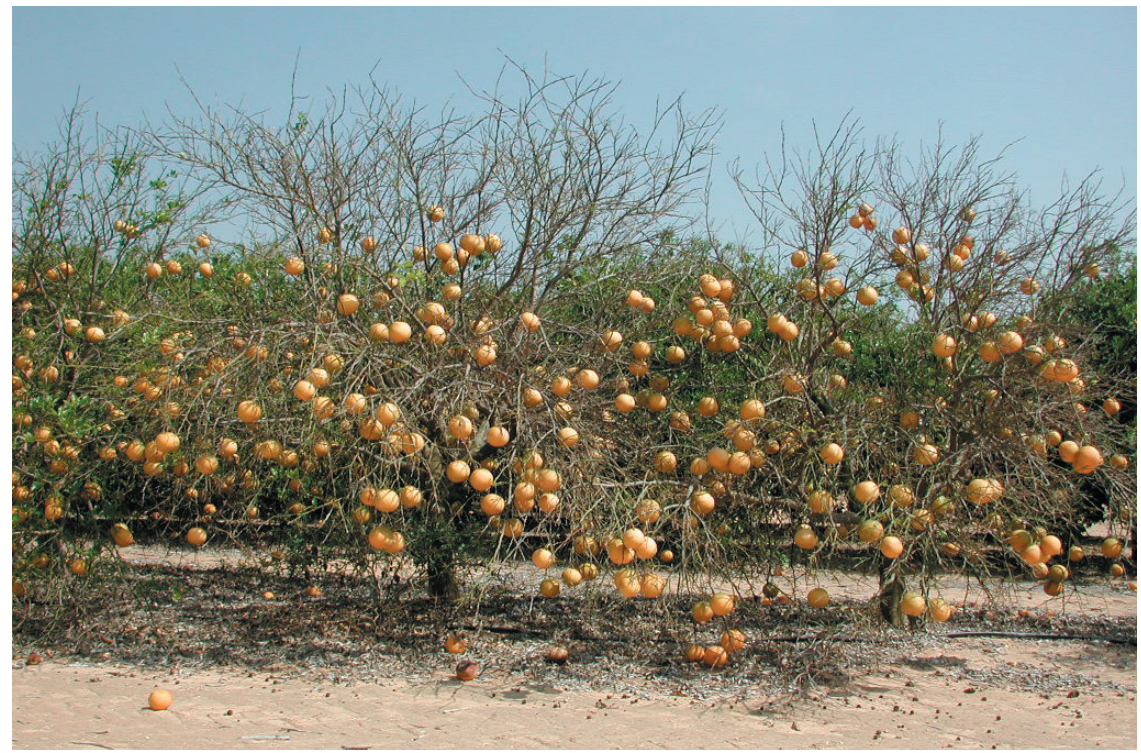

Fig. 1. The appearance of severe salt stress in a commercial grapefruit orchard is shown. The 7-year-old trees were grafted on salt-sensitive rootstock Troyer citrange, and their average leaf chloride content (before defoliation) was about $1.95 \%$ (dry weight).

by the roots. However, chloride may be absorbed directly by leaves when there is direct contact between leaves and irrigation water, as can happen when irrigating with sprinklers (Eaton and Harding, 1959). Once leaf chloride content exceeds a value of $0.7 \%$ (dry matter), we expect "scorching," "firing," or defoliation of leaves, as well as reduction in shoot growth and fruit yield (Fig. 1) (Bañuls and Primo-Millo, 1992; Cole, 1985; Maas, 1993; Storey and Walker, 1999; Xu et al., 2000). Unfortunately, salt-stressed trees are usually identified only after a toxic level of chloride has accumulated and chloride toxicity symptoms are apparent in leaves. As a result, the capability for earlier detection of chloride stress may be of great value. Since chloride usually is absorbed by roots, flows through the stem xylem to the shoot, and accumulates in leaves and fruit, any of these organs can be assessed for potential chloride stress.

This article reviews the use of leaves, fruit, xylem sap, and roots for assessing chloride stress. Although information regarding the effect of salinity on leaves, fruit, stem, and roots chloride content has been partially summarized in some recent excellent reviews (Levy and Syvertsen, 2004; Maas, 1993; Storey and Walker, 1999), their significance for early detection of salt stress was not emphasized. This article will also discuss the methodology used for chloride extraction of the different organs as well as the advantages and disadvantages of different techniques.

\section{Leaf chloride analysis}

Chloride accumulation in leaves is irreversible, and its concentration depends on leaf age (Fig. 2) and the

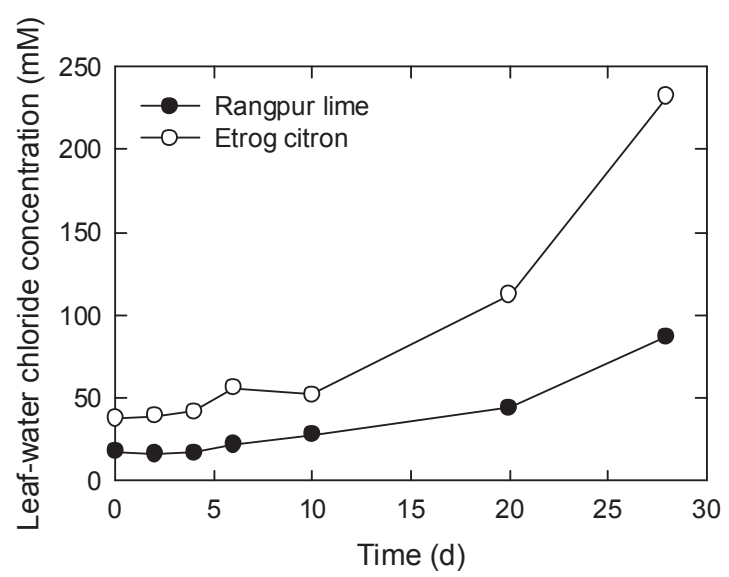

Fig. 2. Leaf chloride was accumulated in 6month-old Rangpur lime (Rang) and Etrog citron (Etrog) seedlings over time. Plants were established in a sand culture and transferred to aerated nutrient solution for 2 weeks before the sodium chloride $(\mathrm{NaCl})$ in the nutrient solution was increased to $50 \mathrm{~mm}$ (adapted from Storey, 1995). 


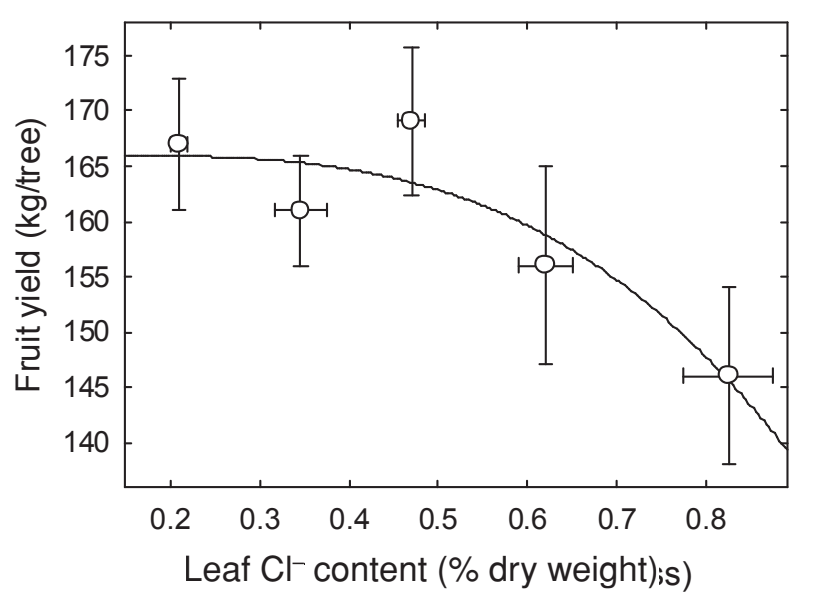

Fig. 3. The relationship between leaf chloride $\left(\mathrm{Cl}^{-}\right)$content and fruit yield of a 7-year-old grapefruit orchard grafted on Troyer citrange is depicted. Tree history, growth conditions, irrigation, and fertilization were as described by Levy et al. (2000). Irrigation salinity treatments ranged from 230 to $800 \mathrm{mg} \cdot \mathrm{L}^{-1}$ (ppm) chloride. Values are mean \pm SE (E. Raveh and Y. Levy, unpublished data); $1 \mathrm{~kg}=2.2 \mathrm{lb}$.

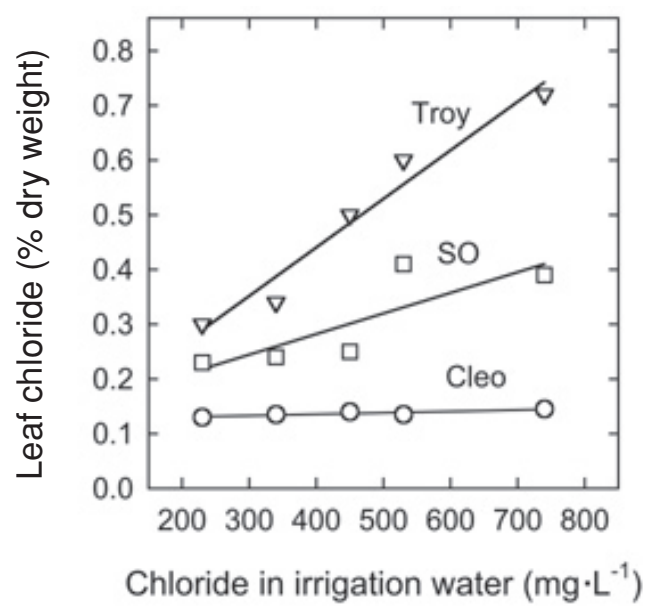

Fig. 4. The effect of salinity and three different rootstocks on chloride accumulation in spring leaves was assessed 6 months after flush. Seven-year-old grapefruit trees, grafted on Troyer citrange (Troy), sour orange (SO), and Cleopatra mandarin (Cleo), were irrigated with saline water containing 230 to $800 \mathrm{mg} \cdot \mathrm{L}^{-1}(\mathrm{ppm})$ chloride. Regression lines were $\mathrm{Y}_{\text {Troy }}=0.09+8.87 \mathrm{X}, \mathrm{R}^{2}$ $=0.96 ; \mathrm{Y}_{\mathrm{SO}}=0.13+3.77 \mathrm{X}, \mathrm{R}^{2}=0.69 ; \mathrm{Y}_{\mathrm{Cleo}}=0.12+$ 2.60X, $\mathrm{R}^{2}=0.79$ (adapted from Levy et al., 2000). transpiration history of the leaf (Moya et al., 2003; Story, 1995). Hence, leaf chloride content does not directly reflect the current chloride uptake by the tree and represents only the total amount of chloride that has accumulated in the leaf from the time it first emerged to the time of chloride analysis. For instance, leaves of a tree that was already exposed to salt stress, but whose soil was leached, will not show a decrease in leaf chloride concentration even though chloride uptake rate was decreased. Leaves achieving toxic concentrations will abscise and be replaced by new ones.

Despite the disconnection between immediate threat of chloride uptake and slow accumulation of chloride in leaves, leaf analysis is the most common method for assessing chloride in citrus. Leaf chloride analysis is easy to perform and is correlated with toxicity symptoms; high leaf chloride levels are always associated with reductions in yield (Fig. 3). Based on "The Citrus Industry" (Embleton et al., 1973), standard leaf chloride assessments are conducted on 5- to 7-month-old spring flush leaves. This method limits sampling to a very narrow period each year. Yet leaf chloride content increases constantly with time (Moya et al., 2003; Story, 1995), and there is no established procedure to assess leaf chloride during the rest of the year.

Exposing trees to saline condi- tions leads to increases in leaf chloride content. The response depends on rootstock performance (Fig. 4). Trees grafted on Troyer citrange (Citrus sinensis $\mathrm{x}$ Poncirus trifoliate), a saltsensitive rootstock, will accumulate more chloride in their leaves than trees grafted on Cleopatra mandarin (C. reshnii), a salt-insensitive rootstock. Leaf chloride accumulation is also affected by the presence of biotic and abiotic stresses (Levy and Syvertsen, 2004). Growth conditions that increase the evaporative demand (e.g., high temperature, low humidity, wind, or drought) (Mass, 1993) or the presence of citrus nematode (Tylenchulus semipenetrans) (Willers and Holdmen, 1980) can enhance chloride accumulation by leaves. More detailed information regarding the interaction between salinity and rootstocks, as well as biotic and abiotic stress, is available in other papers in this workshop.

\section{Juice analysis}

Juice analysis can be conducted as soon as juice-sac cavities are filled, starting at the end of Stage II of fruit development (Spiegel-Roy and Goldschmidt, 1996). Of the four techniques presented in this review, juice analysis is the simplest. It has fewer contamination problems than leaf or root analysis, and is less subject to errors from differences in physiological age; however, it also has major limitations as described below. Sample preparation involves two main steps: squeezing and centrifuging the juice to remove particles such as cell walls, etc. After centrifugation, juice chloride can be analyzed, and the results are usually presented on a molar basis (Levy and Shalhevet, 1990).

The juice analysis technique has mainly been employed for ranking the salt tolerance of citrus rootstocks (García et al., 2002; Levy and Shalhevet, 1990). As with leaves, juice chloride content is strongly affected by soil salinity and can be influenced by rootstock (Fig. 5). Typically, increasing salinity in the soil solution causes an increase in juice chloride content. The magnitude of this increase will be more pronounced in trees grafted on salt-sensitive rootstocks, such as Troyer citrange, than in trees grafted on salt-insensitive ones, such as Cleopatra mandarin and Rangpur lime (C. limonia). There is a positive correlation between juice chloride content and leaf chloride content (Levy and Shalhevet, 1990). However, chloride is accumulated in leaves and fruit at different rates. While leaf chloride concentration can reach $\sim 500 \mathrm{~mm}$ (Story, 1995; Walker, 1986), juice chloride concentration can reach only $\sim 10 \mathrm{~mm}$ (García et al., 2002; Levy and Shalhevet, 1990; Levy et al., 2000). As a result, at any point in time (once fruit juice can be extracted) the correlation between leaf and juice chloride concentration might be differ- 


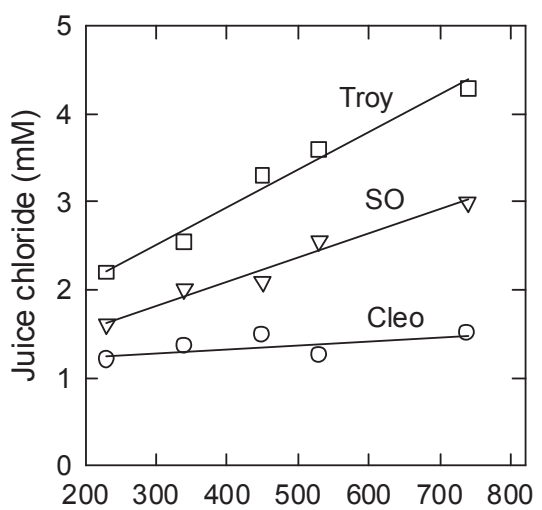

Chloride in irrigation water $\left(\mathrm{mg} \cdot \mathrm{L}^{-1}\right)$

Fig. 5. The effect of salinity and three different rootstocks on juice chloride content is depicted. Seven-year-old grapefruit trees grafted on Troyer citrange (Troy), sour orange (SO), and Cleopatra mandarin (Cleo) were irrigated with saline water containing 230 to $800 \mathrm{mg} \cdot \mathrm{L}^{-1}$ (ppm) chloride.

Regression lines were $\mathrm{Y}_{\text {Troy }}=1.23+$

$4.27 \mathrm{X}, \mathrm{R}^{2}=0.98 ; \mathrm{Y}_{\text {so }}=0.99+2.74 \mathrm{X}$, $\mathrm{R}^{2}=0.97 ; \mathrm{Y}_{\text {Cleo }}=1.15+4.53 \mathrm{X}, \mathrm{R}^{2}=$ 0.43 (adapted from Levy et al., 2000).

ent. Indeed, in the work presented by Levy and Shalhevet (1990), trees of an individual rootstock/scion combination in the same experiment sometimes have similar leaf chloride content, or vice versa [e.g., in 'Marsh' grapefruit (C. paridisi), seedless trees grafted on rough lemon (C. jambhiri), juice chloride content ranged between 5.6 to $6.6 \mathrm{~mm}$ but leaf chloride concentration ranged from $0.5 \%$ to $1.7 \%$ ]. As a result, juice chloride analysis does not reflect the exact toxicity level of the leaves. As in leaves, fruit chloride content continues to accumulate throughout development, and therefore may not reflect the current chloride uptake by the tree.

\section{Xylem sap analysis}

Xylem sap analysis has been used for many years to monitor mineral uptake status of plants (Osonubi et al., 1988; Stark et al., 1985). Sap mineral concentration usually reflects the balance between uptake and internal cycling within the plant. Unlike minerals such as sodium, chloride concentration does not change along the stem (Grieve and Walker, 1983; Raveh and Levy, 2000), and there is no evidence of basipetal transport of chloride in the stem (Story and Walker, 1999, and references therein). Yet, its concentra- tion often varies diurnally (high values at the beginning and the end of the day and low values at noon; Chapin and Van Cleve, 1992). As a result, to develop a method of assessing threat of chloride toxicity, sampling time should be consistent. Sap collection can be done by peeling back the bark and the phloem from a stem segment, placing it in a Scholander pressure bomb, and using a micropipette to collect the sap that exudes (Chapin and Van Cleve, 1992). Sap can also be extracted by centrifugation, which has previously been reported for cavitation experiments (Alder at al., 1997). Mature stem segments [about $1.5 \mathrm{~cm}$ (0.59 inch) in diameter and $12 \mathrm{~cm}$ (4.7 inches) in length ] in which the bark and phloem have been removed, leaving the core xylem, are centrifuged under low temperature $\left[0\right.$ to $1^{\circ} \mathrm{C}\left(32.0\right.$ to $\left.\left.33.8^{\circ} \mathrm{F}\right)\right]$ at a speed that will generate the desired extraction pressure. The extraction pressure should be within the natural range of pressure that exists within the stem (Chapin and Van Cleve, 1992) and can be calculated as described by Alder et al. (1997):

$$
P_{r}=0.5 p \omega^{2}\left(r^{2}-r_{\text {max }}^{2}\right)
$$

where $P_{r}$ is water column pressure at distance $r(\mathrm{~Pa})$ during the extraction, $p$ is the water density $\left(\mathrm{kg} \cdot \mathrm{m}^{-3}\right), \omega$ is our angular velocity $(\mathrm{rad} / \mathrm{s})$, and $r$ is the sample distance from axis of rotation $(\mathrm{m})$. Since the centrifuge extraction technique is conducted at low temperatures, the concentration of chloride in the xylem sap is less affected by evaporation than in the Scholander pressure bomb technique. Moreover, the centrifuge technique enables simultaneous extraction of a number of stem segments.

Xylem sap chloride concentration is positively correlated to current soil salinity (Fig. 6). Increases in soil salinity are followed by an increase in sap chloride concentration. Under high salinity, xylem sap chloride content reaches a plateau. The average daily xylem sap chloride concentration ranges from about $0.5 \mathrm{~mm}$ to about $20 \mathrm{~mm}$, and its concentration is affected by rootstock performance and growth conditions (Moya et al., 2003; Storey, 1995). Stem sap flow measurements (Cohen, 1991; Cohen and Naor, 2002) indicate that xylem sap is completely replaced several times a day as new water is taken up by the roots (depending on transpiration conditions and water status of the soil). Hence, xylem sap analysis should reflect the current chloride uptake by the tree. Indeed, leaching the soil in a salinity-stressed orchard is followed by an immediate decrease in xylem sap chloride content (Raveh and Levy, 2000). In contrast to leaf chloride levels, xylem sap chloride concentration is correlated with the current chloride uptake, but not necessarily with leaf chloride levels, which will be reflected in overt symptoms of toxicity. Nevertheless, it is quite clear that maintaining high chloride in xylem sap for a long period will result in high leaf chloride content.

\section{Root chloride analysis}

Roots are the first tissue to be exposed to any variation in soil solution salinity. The analysis procedure is similar to the procedure used for leaf chloride analysis: rinse roots with deionized water, dry in a forced-draft oven at 50 to $70{ }^{\circ} \mathrm{C}(122.0$ to 158.0 $\left.{ }^{\circ} \mathrm{F}\right)$, grind, and extract. The results

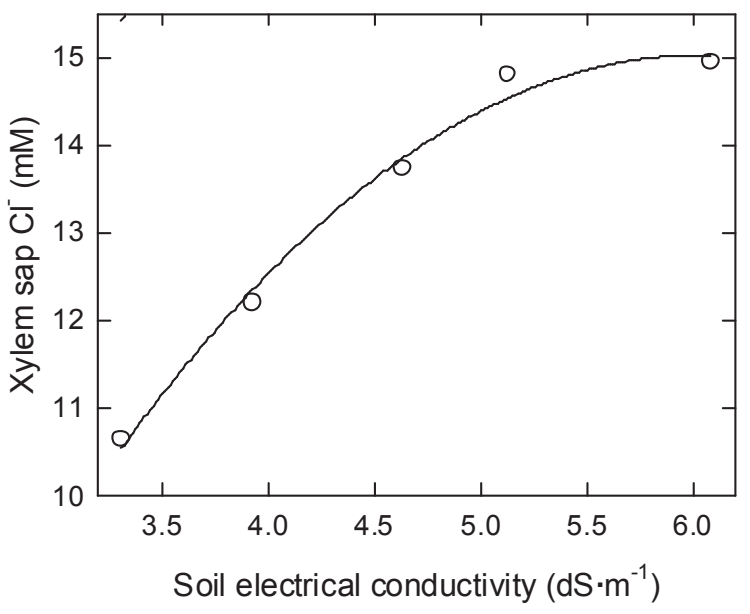

Fig. 6. The relationship between soil saturation extract electric conductivity $\left(\mathrm{EC}_{\mathrm{e}}\right)$ and daytime xylem sap chloride $\left(\mathrm{Cl}^{-}\right)$concentration in 7-year-old grapefruit trees grafted on Troyer citrange is shown. Soil samples were taken from the upper $80 \mathrm{~cm}(31.5$ inches). Stem segments were sampled between 0900 and $1000 \mathrm{HR}$. Growth conditions, irrigation, and fertilization were as described by Levy et al., 2000 (E. Raveh, unpublished data). 


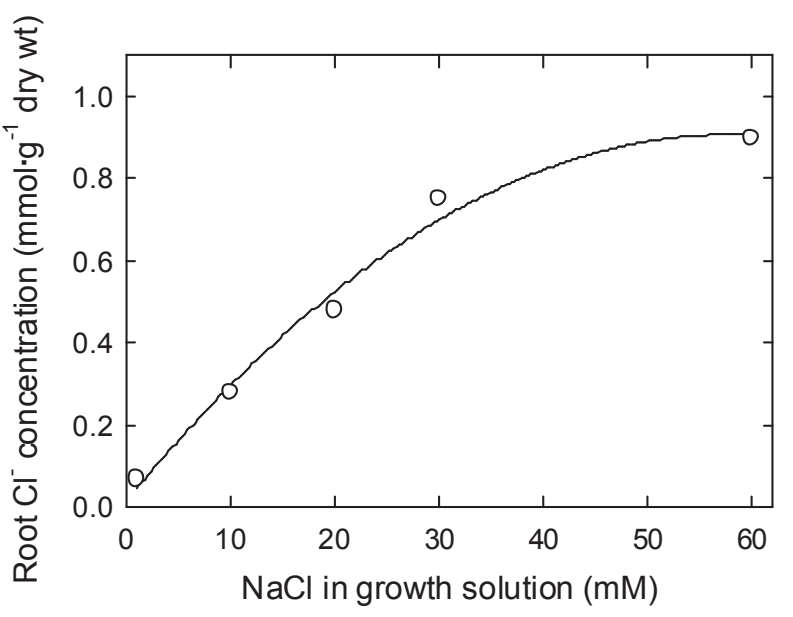

Fig. 7. The effect of salinity on sour orange seedling root chloride $\left(\mathrm{Cl}^{-}\right)$concentration is shown. Seedlings were grown in nutrient solution containing $1,10,20$, 30 , or $60 \mathrm{~mm}$ sodium chloride $(\mathrm{NaCl})$. Data present the chloride analysis from root segments, taken 15 to $45 \mathrm{~mm}$ ( 0.59 to 1.77 inch) from distal end of root, as measured on day 14 (adapted from Fernández-Ballester et al., 2003).

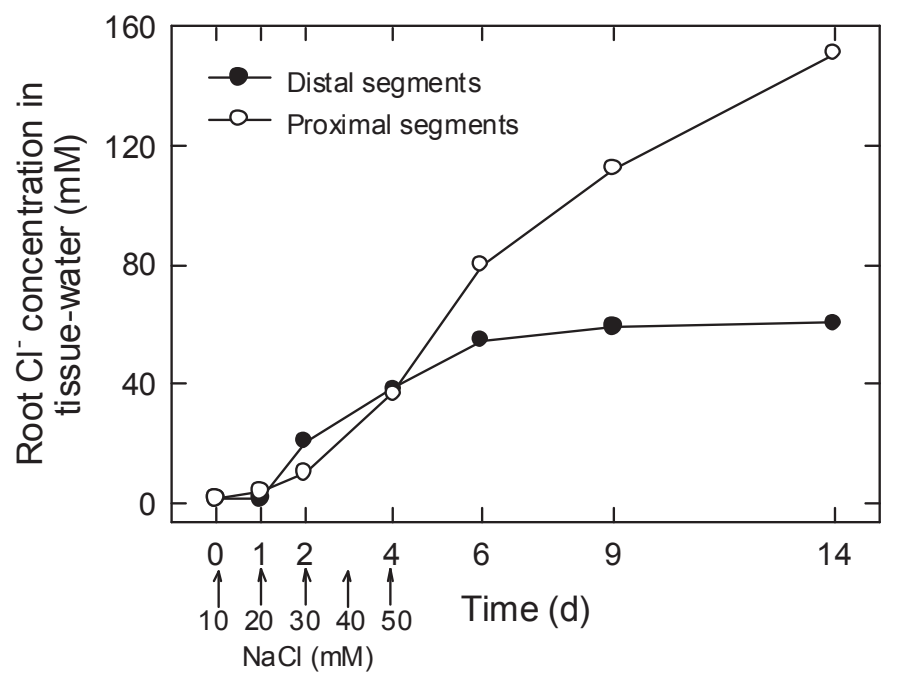

Fig. 8. Changes occurred in chloride $\left(\mathrm{Cl}^{-}\right)$concentration in distal [ 2 tol $2 \mathrm{~mm}(0.08-0.47$ inch)] (Dist) and proximal [40 to 50 mm (1.57-1.97 inch)] (Prox) root segments of Rangpur lime during acclimation to $50 \mathrm{~mm}$ sodium chloride $(\mathrm{NaCl})$. Sequential increases in $\mathrm{NaCl}$ of $10 \mathrm{~mm}$ per day were made from day 0 to day 4 (arrows) (adapted from Storey and Walker, 1987). can be presented on a molar basis or on a dry weight basis (Cerezo et al., 1999; Storey, 1995). The results of such extraction, however, reflect both symplast and apoplast chloride content. If we are interested in measuring only symplast chloride concentration, the apoplast chloride should first be leached (Altman and Mendel, 1973).

Similar to leaf, juice, and xylem sap, root chloride content is correlated with soil salinity (Fig. 7) (FernándezBallester et al., 2003). Increasing soil salinity is followed by an increase in root chloride content. However, unlike leaves, root chloride concentration will not continually increase; after several days it will reach a plateau and stabilize (Fernández-Ballester et al., 2003; Storey, 1995; Storey and Walker, 1987). As a result, like xylem sap analysis, root chloride content correlates only with the current chloride uptake and may not reflect leaf toxicity levels. Zekri and Parsons (1992) also concluded that there is no relationship between root and leaf chloride concentration. Root chloride content might also be affected by rootstock performance; roots of salt-sensitive rootstocks will usually be characterized by higher chloride concentration than roots of salt-tolerant rootstocks (Bañules et al., 1990; Storey and Walker, 1987). However, some exceptions can be found (Moya et al., 2003). As in leaves, root age (distance from root tip) may also affect root chloride equilibrium and content (Fig. 8). Distal roots (younger roots) will reach the plateau earlier than proximal roots (older roots), and will be characterized by lower chloride concentration (Fernández-Ballester et al., 2003; Storey, 1995; Storey and Walker, 1987). The effect of decreasing soil salinity on root chloride content has not been appropriately studied.

Unlike potted plant experiments, where soil solution salinity around the root system is relatively uniform, soil salinity around the roots of orchard trees is characterized by heterogeneity between and within soil layers (Xu et al., 2000). While heterogeneous soil salinity distribution can be overcome by extensive soil sampling, the relative contribution of roots of the different soil sections to the total chloride uptake remains unknown. As a result, root analysis in orchard trees cannot serve as a reliable tool for monitoring the average current chloride uptake of the tree.

\section{Conclusions}

Potential chloride stress depends on both the current leaf chloride content and the current chloride uptake by the tree. Leaf chloride content, which is the traditional means of assessing citrus chloride status, does reflect the current toxicity level of the tree (how much chloride has already been accumulated by leaves), but does not reflect the current chloride uptake status, which is better measured by xylem sap and root analysis, and indicates the future potential increase in leaf chloride content. Juice analysis neither reflects the leaf chloride toxicity level nor the current chloride uptake status. Since root analysis under field conditions is more difficult and may be heterogeneous due to spatial variability in soil chloride content, we propose that a combination of xylem sap chloride analysis and leaf chloride analysis is the most useful analysis for assessing potential chloride stress in citrus trees. A model that integrates these two parameters, along with seasonal transpiration rates, should be developed for more accurately monitoring and controlling potential chloride toxicity in citrus trees.

\section{Literature cited}

Alder, N.N., W.T. Pockman, J.S. Sperry, and S. Nuismer. 1997. Use of centrifugal force in the study of xylem cavitation. J. Expt. Bot. 48:665-674.

Altman, A. and K. Mendel. 1973. Characteristics of the uptake mechanism of chloride ions in excised roots of a woody plant (citrus). Physiol. Plant. 29:157-162.

Bañules, J., F. Legaz, and E. Primo-Millo. 1990. Effect of salinity on uptake and distribution of chloride and sodium in some citrus scion-rootstock combinations. J. Hort. Sci. 65:715-724. 
Bañules, J. and E. Primo-Millo. 1992. Effects of chloride and sodium on gas exchange parameters and water relations of citrus plants. Physiol. Plant. 86:115-123.

Cerezo, M., P. García-Agusín, and E. Primo-Millo. 1999. Influence of chloride and transpiration on net ${ }^{15} \mathrm{NO}_{3}$ - uptake rate by citrus root. Ann. Bot. 84:117-120.

Chapin, F.S. III and K. Van Cleve. 1992. Approaches to studying nutrient uptake, use and loss in plants. p. 195-199. In: Pearcy, R.W., J. Ehleringer, H.A. Mooney, and P.W. Rundel (eds.) Plant physiological ecology: Field methods and instrumentation. Chapman and Hall. London.

Cohen, Y. 1991. Determination of orchard water requirement by a combined trunk sap flow and meteorological approach. Irr. Sci. 12:93-98.

Cohen, S. and A. Naor. 2002. The effect of tree rootstocks on water use, canopy conductance and hydraulic parameters of apple trees and predicting canopy from hydraulic conductance. Plant Cell Environ. $25: 17-28$

Cole, P.J., 1985. Chloride toxicity in citrus. Irr. Sci. 6:63-71.

Eaton, F.M. and Harding, R.B. 1959. Foliar uptake of salt constituents of water by citrus plants during intermittent sprinkling and immersion. Plant Physiol. 33:22-26.

Embleton, T.W., W.W. Jones, C.K. Labanauskas, and W. Reuther. 1973. Leaf analysis as a diagnostic tool and guide to fertilization. p. 183-210. In: W. Reuther (ed.). The citrus industry. Vol. III. Univ. of California, Berkeley.

Fernández-Ballester, G., F. García-Sánchez, A. Cerdá, and V. Martínez. 2003. Tolerance of citrus rootstock seedlings to saline stress based on their ability to regulate ion uptake and transport. Tree Physiol. 23:265-271.

García, M.R., G.P. Bernet, J. Puchades, I. Gómez, E.A. Carbonell, and M.J. Asíns. 2002. Reliable and easy screening technique for salt tolerance of citrus rootstocks under controlled environments. Austral. J. Agr. Res. 53:653-662.

Grieve, A.M. and R.R. Walker. 1983. Uptake and distribution of chloride, sodium and potassium ions in salt-treated citrus plant. Austral. J. Agr. Res. 34:133-143.

Levy, Y., E. Raveh, and Y. Lifshitz. 2000. The effect of rootstock and nutrition on the response of grapefruit trees to salinity. Proc. Intl. Soc. Citricult. 9:334-337.

Levy, Y. and J. Shalhevet. 1990. Ranking the salt tolerance of citrus rootstocks by juice analysis. Scientia Hort. 45:89-98.
Levy, Y. and J.P. Syvertsen. 2004. Irrigation water quality and salinity effects in citrus trees, p. 37-82. In: J. Janick (ed.). Hort. Rev., Vol. 30. Wiley, Hoboken, N.J.

Maas, E.V. 1993. Salinity and citriculture. Tree Physiol. 12:195-216.

Moya, J.L., A. Gómez-Cadenas, E. PrimoMillo, and M. Talon. 2003. Chloride absorption in salt-sensitive Carrizo citrange and salt-tolerant Cleopatra mandarin citrus rootstocks is linked to water use. J. Expt. Bot. 54:825-833.

Osonubi, O., R. Oren, K.S. Werk, E.D. Schulze, and H. Heilmeier. 1988. Performance of two Picea abies (L.) Karst. stands at different stages of decline. IV. Xylem sap concentrations of magnesium, calcium, potassium and nitrogen. $\mathrm{Oeco}^{-}$ logia $77: 1-6$.

Raveh, E. and Y. Levy. 2000. Analysis of xylem water as an indicator of current chloride uptake status in trees. Intl. Soc. Citricult. IXth Congr., Orlando, Fla. 3-7 Dec. Abstr. 263. p. 138.

Spiegel-Roy, P. and E. Goldschmidt. 1996. Biology of citrus. p. 88-111. Cambridge Univ. Press, New York.

Stark, N., C. Spitzner, and D. Essig. 1985. Xylem sap analysis for determining nutritional status of trees: Pseudotsuga menziesii. Can. J. For. Res. 15:429-437.

Storey, R. 1995. Salt tolerance, ion relations and the effect of root medium on the response of citrus to salinity. Austral. J. Plant Physiol. 22:101-114.

Storey, R. and R.R. Walker. 1987. Some effects of root anatomy on $\mathrm{K}, \mathrm{Na}, \mathrm{Cl}$, loading of citrus roots and leaves. J. Expt. Bot. 38:1769-1780.

Storey, R. and R.R. Walker. 1999. Citrus and salinity. Scientia Hort. 78:39-81.

Walker, R.R. 1986. Sodium exclusion and potassium-sodium selectivity in salttreated trifoliate orange (Poncirus trifoliata) and Cleopatra mandarin (Citrus reticulata) plants. Austral. J. Plant Physiol. 13:293-303.

Willers, P. and E. Holdmen. 1980. The influence of citrus nematodes, Tylenchulus semipenetrans, on the performance of trees growing under saline conditions. Subtropica 1:13-16.

Xu, G.H., H. Magen, J. Tarchitzky, and U. Kafkafi. 2000. Advances in chloride nutrition of plants. Adv. Agron. 68:97-150.

Zekri, M. and Parsons, L.R. 1992. Salinity tolerance of Citrus rootstocks: Effects of salt on root and leaf mineral concentrations. Plant Soil 147:171-181. 